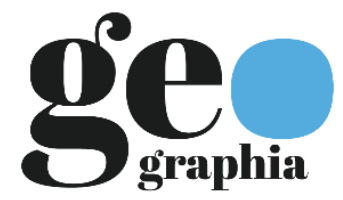

ARTIGOS

\title{
QUAL RACIOCÍNIO? QUAL GEOGRAFIA? CONSIDERAÇÕES SOBRE O RACIOCÍNIO GEOGRÁFICO NA BASE NACIONAL COMUM CURRICULAR
}

\author{
Eduardo Donizeti Girotto ${ }^{1}$
}

Universidade de São Paulo

Enviado em 19 ago. 2020 | Aceito em 4 jul. 2021

Resumo: Buscamos, neste texto, problematizar o sentido hegemônico do raciocínio geográfico na Base Nacional Comum Curricular (Ensino Fundamental e Médio), apontando a necessidade de ressignificarmos este conceito a partir, de um lado, do seu lugar na história e epistemologia da geografia; de outro, do entendimento da dimensão espacial, complexa e contraditória, da sociedade em que vivemos. Entre as conclusões da pesquisa, apontamos como o conceito de raciocínio geográfico expresso na BNCC pouco dialoga com a epistemologia da geografia. Destacamos que este esvaziamento epistemológico é intencional e se funda em um projeto político que concebe a formação docente a partir de uma perspectiva técnico instrumental, o que se confirma com o lançamento da Base Nacional de Formação de Professores em 2019. Assim, tecemos algumas considerações no sentido de apresentar possibilidades de um outro conceito de raciocínio geográfico que, retomando o diálogo com diferentes autores da história do pensamento geográfico, contribua para que os sujeitos tomem consciência de suas condições espaciais em um mundo marcado pela expropriação e alienação espacial, um dos elementos fundantes do modo de produção capitalista.

Palavras-chave: Raciocínio Geográfico; BNCC, Ensino de Geografia

\section{WHAT REASONING? WHAT GEOGRAPHY? CONSIDERATIONS ON GEOGRAPHICAL REASONING ON THE CURRICULAR COMMON NATIONAL BASIS}

Abstract: We seek, in this text, to problematize the hegemonic sense of geographic reasoning in the Common National Curriculum Base (Elementary and High School), pointing out the need to re-signify this concept from, on the one hand, its place in the history and epistemology of geography; on the other, understanding the complex and contradictory spatial dimension of the society in which we live. Among the conclusions of the research, we point out how the concept of geographical reasoning expressed in the BNCC has little to do with the epistemology of geography. We emphasize that this epistemological emptying is intentional and is based on a political project that conceives teacher training from an instrumental technical perspective, which is confirmed with the launch of the National Teacher Training Base in 2019. Thus, we make some considerations in the sense of presenting possibilities for another concept of geographic reasoning that, resuming the dialogue with different authors in the history of geographic thought, contributes to the subjects becoming aware of their spatial conditions in a world marked by expropriation and spatial alienation, one of the founding elements of the capitalist mode of production. Keywords: Geographic Reasoning; BNCC, Geography Teaching

\section{GEOQUÍMICA Y PETROGRAFÍA DE DEPÓSITOS CUTERNARIOS DE LA PORCIÓN SW DE PRAIA BRAVA, ARMAÇÃO DOS BÚZIOS, RJ, BRASIL: EDFRXY DIFFRACCIÓN LÁSER}

Resumen: En este texto, buscamos problematizar el sentido hegemónico del razonamiento geográfico en la Base Curricular Nacional Común (Bachillerato y Bachillerato), señalando la necesidad de replantear este concepto desde, por un lado, su lugar en la historia y epistemología de geografía; por otro, la comprensión de la compleja y contradictoria dimensión espacial de la sociedad en la que vivimos. Entre los hallazgos de la investigación, señalamos cómo el concepto de razonamiento geográfico expresado en el BNCC no dialoga con la epistemología de la geografía. Destacamos que este vaciamiento epistemológico es intencional y se sustenta en un proyecto político que concibe la formación docente desde una perspectiva técnico-instrumental, lo cual se confirma con el lanzamiento de la Base Nacional de Formación Docente en 2019. sentido de presentar posibilidades de otro concepto de geografía razonamiento que, retomar el diálogo con diferentes autores de la historia del pensamiento geográfico, contribuye a que los sujetos tomen conciencia de sus condiciones espaciales en un mundo marcado por la expropiación y alienación espacial, uno de los elementos fundacionales del modo de producción capitalista. Palabras clave: Razonamiento geográfico; BNCC, Enseñanza de la geografía

1. ${ }^{1}$ Professor Doutor do Departamento de Geografia da Universidade de São Paulo. Coordenador do Laboratório de Ensino e Material Didática (LEMADI-USP) e membro da Rede Escola Pública e Universidade (REPU). Email: egirotto@usp.br ORCID: https://orcid.org/0000-0002-9870-6188 
Introdução

Presente na última versão da Base Nacional Comum Curricular (BNCC), o conceito de raciocínio geográfico tem longa história na formação da geografia como ciência e como disciplina escolar. Trata-se de um dos princípios que fundamenta esta área do conhecimento e, por isso, discutir o lugar do raciocínio geográfico na história e epistemologia da geografia é, em nossa visão, uma das formas de avançarmos na compreensão deste conceito que tem ganhado destaque nos últimos anos. Como fundamento do fazer geográfico, pode revelar os sentidos políticos e ideológicos da geografia que se faz, bem como evitar o esvaziamento teórico-conceitual deste princípio, o que é próprio dos movimentos de reformas curriculares sob a ótica neoliberal.

Em nossa perspectiva, a centralidade que tal conceito tem assumido na BNCC não pode ser lido como avanço de uma perspectiva crítica do/no ensino de geografia. Ao contrário, os inúmeros silêncios da BNCC, principalmente no campo da epistemologia, acerca de elementos fundamentais para se compreender e desenvolver raciocínios geográficos complexos revelam as possíveis intencionalidades que o documento e seus autores buscam ocultar e vão na contramão dos processos de retomada de importantes debates acerca da história e da epistemologia da geografia na escola e na universidade.

Inúmeros autores têm abordado questões acerca do raciocínio geográfico na história e na epistemologia da geografia. Claval (2010) traz importantes contribuições ao localizar os saberes geográficos como fundantes da vida cotidiana dos homens e mulheres em diferentes lugares e organizações sociais, seja na forma como nomeiam os lugares e a relação que estabelecem com eles, seja nas estratégias que criam para plantar, morar, se deslocar, guerrear, entre outras. Assim, a geografia preexiste à sua sistematização enquanto ciência e disciplina escolar, e isto é um dos elementos centrais no entendimento das múltiplas articulações possíveis entres estas duas dimensões. Isso significa reconhecer que não foram a escola e a universidade, instituições basilares da modernidade, que inventaram a geografia. Ao contrário, contribuíram no intenso processo de sistematização, organização e classificação destes saberes imersos na vida cotidiana. Em nossa perspectiva, é fundamental que esta relação dialética entre a geografia como ciência/disciplina e como saber cotidiano, conforme apontado por Claval, mantenha-se sempre em evidência e movimento, ainda mais se o foco for desenvolver raciocínios geográficos cada vez mais complexos.

Dando continuidade ao debate, Gomes (2017) apresenta uma densa discussão a partir da ideia de que a geografia é uma forma de ver e pensar, interessada na localização dos fenômenos, na "ordem espacial do mundo". Trata-se de, retornando a Kant e Humboldt, reafirmar os princípios que têm marcado o fazer geográfico nos últimos 200 anos e que se assentam na busca de respostas para a pergunta: por que isto está onde está?

\footnotetext{
Agora, vejam a ousadia, sugerimos não apenas que essa ocupação sobre os sistemas de localização funciona como um dado preliminar e fundador, sendo o objeto central da disciplina, mas também acrescentamos que isso compõe uma forma de pensar. Criam-se imagens e desenhos por meio das quais somos desafiados a produzir sentido na variedade de elementos que aparecem sem o artifício da seleção antes daquilo que vamos considerar, pois não impomos o deslocamento das coisas do lugar onde aparecem e vivem (GOMES, 2017, p. 18)
}

A ideia da geografia como uma forma de pensar e ver é, em nossa perspectiva, potente para pensarmos os processos de ensinar-aprender geografia no mundo contemporâneo. Se concebemos a educação como um processo amplo de formação, é fundamental que mais importante do que a apropriação de uma lista extensa de conteúdos, os estudantes possam construir novos sentidos e 
leituras da realidade a partir de tais conteúdos que não são, a priori, geográficos. O que torna um conteúdo "geográfico", são as perguntas que fazemos a ele, com ênfase na localização, na conexão, na correlação, na comparação, todos princípios metodológicos que buscam enfatizar a dimensão espacial da realidade.

Assim, para avançarmos neste debate, o objetivo deste texto é problematizar o sentido hegemônico do raciocínio geográfico na BNCC, apontando a necessidade de ressignificarmos este conceito a partir, de um lado, do seu lugar na história e epistemologia da geografia; de outro, do entendimento da dimensão espacial, complexa e contraditória, da sociedade em que vivemos.

Para isso, problematizamos como o conceito de raciocínio geográfico expresso na BNCC pouco dialoga com os diferentes autores e autoras que construíram tal conceito, fazendo com que aquilo que está expresso no documento se aproxime mais de uma palavra na moda do que efetivamente de um princípio teórico-metodológico para ensinar e aprender geografia no interior de uma perspectiva crítica, entendida aqui como movimento de método que articula denúncia e anúncio, nos termos propostos por Freire (1987). Por fim, tecemos algumas considerações no sentido de apresentar possibilidades de um outro conceito de raciocínio geográfico que, retomando o diálogo com diferentes autores da história do pensamento geográfico, contribua para que os sujeitos tomem consciência de suas condições espaciais em um mundo marcado pela expropriação e alienação espacial, um dos elementos fundantes do modo de produção capitalista.

Os debates e discussões aqui apresentados são resultados das pesquisas desenvolvidas no Laboratório de Ensino e Material Didático do Departamento de Geografia da Universidade de São Paulo, no âmbito do projeto "Atlas da Educação Brasileira: 2010-2018.

\section{Do objeto ao raciocínio: retomando princípios epistemológicos}

Qual é o objeto de geografia? Talvez esta seja a pergunta mais repetida na escola e na universidade nos últimos 40 anos, o que, possivelmente, a tenha tornado um obstáculo epistemológico, nos termos propostos por Bachelard (1996):

O historiador da ciência deve tomar as ideias como se fosse fatos. O epistemólogo deve tomar os fatos como se fossem ideias, inserindo-as num sistema de pensamento. Um fato mal interpretado por uma época permanece, para o historiado, um fato. Para o epistemólogo, é um obstáculo, uma contra-pensamento (p. 22)

Tomado como fato, tal pergunta oculta um elemento importante: a busca por um objeto não percorreu a história e a epistemologia da geografia de forma linear, não se constituindo, inclusive, como questão importante para um conjunto de autores e autoras deste campo científico/disciplinar. Por isso, de partida, anunciamos que não nos interessa percorrer o caminho em busca do objeto da geografia, rechaçando o pressuposto de que a definição dele seria suficiente para garantir o estatuto epistemológico e científico deste campo do conhecimento, inclusive a sua manutenção como disciplina escolar. Em nosso ponto de vista, o objeto da geografia é o mesmo de todas as ciências: a realidade, tomada aqui de forma ampla e como próprio resultado da interpretação socialmente construída do que este termo venha a ser. O que nos interessa é compreender de que forma a ciência geográfica busca compreendê-la, o que significa, nestes termos, falar de princípios e métodos. É deste lugar que buscaremos discutir o raciocínio geográfico.

Diante da amplitude do termo, nosso objetivo é estabelecer breves diálogos com autores que contribuíram na consolidação deste debate na ciência geográfica. Como princípio, o raciocínio geográfico está expresso nas obras dos primeiros geógrafos. Podemos encontrá-lo no decorrer dos 
textos escritos por Alexander Von Humboldt, principalmente no que se refere a ênfase que o autor dá a conexão espacial entre os fenômenos, um dos elementos definidores do raciocínio geográfico. No famoso mapa "Geografia das plantas equinociais" é possível verificar uma preocupação do autor em descrever, analisar e construir conexões espaciais entre fenômenos como tipos de plantas, altitude, mudanças na temperatura, na pressão atmosférica etc. Construindo primeiro na escala local, tal princípio da conexão espacial dos fenômenos vai ser desenvolvido por Humboldt em diferentes obras, alçando o mais alto grau de complexidade em sua obra principal, "Cosmos", no qual o autor busca estabelecer conexões espaciais entre diversos fenômenos em diferentes escalas.

É importante destacar que o princípio da conexão espacial dos fenômenos aponta para certo limite da crítica feitas aos primeiros autores da geografia como ciência moderna, muitas vezes acusados do uso excessivo da descrição. Nos textos de Humboldt, a descrição é desenvolvida como uma etapa da construção de conexões espaciais, momento do método pelo qual a ciência geográfica lê e interpreta a realidade. Não se trata de uma descrição com um fim em si mesma. Disso decorre a importância dos mapas, cartas, tabelas nos materiais produzidos por Humboldt, na construção de sínteses interpretativas que possibilitem aos leitores a visualização destas conexões em escala mundial. Segundo Wulf (2016, p.139),

\begin{abstract}
Quando retornaram do Chimborazo, Humboldt estava pronto para formular sua nova visão de natureza. Nos contrafortes andinos, ele começou a esboçar a sua assim chamada Naturgemalde - um termo alemão intraduzível que pode significar "pintura da natureza", mas que também implica uma ideia de unidade ou todo. Era, conforme Humboldt explicou mais tarde, um "microcosmo em uma só página". Ao contrário dos cientistas que anteriormente haviam classificado o mundo natural em unidades taxonômicas no âmbito de uma rigorosa hierarquia, preenchendo intermináveis tabelas como categorias, Humboldt produzia um desenho. "A natureza é um todo vivo", disse ele mais tarde, não um "agregado morto"
\end{abstract}

Esta busca de intepretações espaciais dos fenômenos em diferentes escalas pode ser encontrada também nas obras de Carl Ritter (1779-1859) e Eliseé Reclus (1930-1905), naquilo que os autores denominaram de geografia comparada. Trata-se de uma lógica de pensamento que busca, a todo o momento, questionar como os fenômenos se comportam em diferentes lugares, buscando identificar permanências e rupturas. Trata-se de uma compreensão da importância da totalidade no processo de construção da análise geográfica, tornando um falso problema de método a dicotomia entre geografia regional e geografia universal. Regional, universal, local só fazem sentido na análise geográfica quando postos em relação e, por isso, a necessidade de compreender o singular como parte de conexões mais amplas.

No Brasil, um dos primeiros autores ao tratar do raciocínio geográfico foi Delgado de Carvalho. No início do século XX, o autor desempenhou papel fundamental na renovação teórico-metodológica da geografia e na sua consolidação como ciência e como disciplina escolar. Até então, a geografia, ainda inexistente como ciência nas universidades, era tratada de forma conteudista nos cursos secundários, o que a faz, até hoje, em muitos casos, ser pensada como uma ciência desinteressante, desconectada da vida dos estudantes. E foi contra esta perspectiva que Delgado de Carvalho teceu suas principais críticas.

Em um dos seus textos, "O sentido geográfico", originalmente a aula de abertura do curso de formação continuada de professores de geografia na Universidade do Ar, o autor discute acerca da maneira como a geografia compreende a realidade. Em seu texto, busca superar alguns lugares comuns acerca da ciência geográfica: 
Foi assim que ouvi dizer ser a geografia a descrição da terra, do habitat do homem; depois foi me dito que a geografia era uma ciência das relações, principalmente entre a natureza e o homem; mais tarde, me ensinaram que a geografia é essencialmente uma distribuição de fenômenos sobre a superfície da Terra. Em não falo dos que me quiseram fazer acreditar que a geografia é apenas conhecimento dos lugares e que um bom geógrafo é um bom memorizador de nomes próprios. Em todo caso, muito mais de vinte minutos gastaria eu aqui, se quisesse lembrar tudo quanto ouvi, li e aprendi a respeito do campo verdadeiro da geografia (CARVALHO, 1945, p. 7)

Para Delgado, o que faz de um objeto um objeto geográfico é a ênfase em sua localização, aquilo que denomina de sentido geográfico. E aqui temos um elemento central para discutirmos o raciocínio geográfico como princípio da geografia: a localização como ponto de partida da análise da realidade. Trata-se de reconhecer que a localização dos fenômenos importa como um dos elementos a ser levado em consideração nas interpretações que iremos construir sobre a realidade. Isso não significa reduzi-la apenas a dimensão de localização, o que poderia, facilmente, resultar em determinismos geográficos. Mas discutir e interpretar o porquê das localizações dos fenômenos, compreendendo-as como expressão de processos sociais e naturais, é um dos elementos centrais no desenvolvimento do raciocínio geográfico, de fundamental importância também nos processos de educação geográfica.

\section{Das localizações às situações}

A importância da localização dos fenômenos ganha novos contornos na história da geografia a partir da obra de Pierre George e do movimento da Geografia Ativa. Este movimento tem como principal forma de divulgação de seus fundamentos a obra de mesmo nome. A justificativa e os fundamentos que levaram a construção desta obra estão na necessidade de, naquele momento de transformação socioespacial de toda sociedade, refundar as bases teóricas e metodológicas da geografia. Não era possível utilizar as mesmas categorias interpretativas, os mesmos procedimentos metodológicos, os mesmos instrumentais e ferramentas para se compreender uma sociedade em mutação, diferente daquela descrita pelos geógrafos e geógrafas do século XIX.

Este contexto de mudança traz uma série de desafios, principalmente, de ordem teórica e metodológica. É preciso reformular as lógicas de interpretação do mundo. Naquele momento da produção do conhecimento geográfico, muitos geógrafos tinham optado pelo caminho da especialização. Tal caminho, segundo os autores da Geografia Ativa, contribuía para a perda de sentido acerca da especificidade deste campo do conhecimento, "não durando além do que duraram suas razões de ser" (GEORGE et al, 1966, p.15).

Para os autores, a hiperespecialização do conhecimento geográfico rompia com a aquilo que definia a geografia como uma ciência, qual seja, a sua capacidade de realizar a síntese a partir da conexão espacial de fenômenos, buscando causas e consequências relacionadas aos mesmos. Porém, o que se via, com a hiperespecialização era um procedimento cada vez mais analítico, com interpretações geográficas fragmentadas. Neste processo,

Os geógrafos que são levados a se especializarem também perdem sua personalidade e comprometem em curto prazo suas vantagens. Porque o dilema é inelutável: ou bem se é tão altamente especializado quanto o técnico para poder enfrentá-lo em seu terreno, e para isso aprende-se uma segunda profissão; como para tal fim é preciso consagrar todo o seu tempo, sacrifica-se a cultura sintética do geógrafo, deixa-se de seguir os trabalhos de geografia humana, porque se quer fazer geografia aplicada em pedologia ou em sedimentologia - ou bem faz-se questão de continuar geógrafo, e então, é sábio mostrar-se mais modesto no 
domínio da especialização e limitar-se a aconselhar, a auxiliar, enfim a enquadrar o trabalho dos especialista (GEORGE et al, 1966, p. 31)

Para que esta perda de sentido do que é fazer geografia não ocorresse, era necessário que se torneassem mais evidentes as ações e procedimentos específicos da geografia que lhe davam a capacidade de dialogar e contribuir com outras e de ampliar o conhecimento acerca da realidade. Neste sentido, para os autores da Geografia Ativa, o conceito de situação estaria no centro do raciocínio geográfico se configurando enquanto especificidade desta ciência. Desvendada a situação em seus processos formativos, poderia o geógrafo contribuir para a produção de uma leitura socioespacial sintética dos fenômenos. O conceito de situação permitiria, portanto, ao geógrafo desenvolver um arcabouço teórico-metodológico com vistas ao desenvolvimento de pesquisas e processos de ensino-aprendizagem que delimitassem a especificidade deste campo científico sem, ao mesmo tempo, romper o diálogo com outros campos do saber. Para os autores,

Uma situação é a resultante, num dado momento - que é, por definição, o momento presente, em geografia - de um conjunto de ações que se contrariam, se moderam ou se reforçam e sofrem os efeitos de acelerações, de freios ou de inibição por parte dos elementos duráveis do meio e das sequelas das situações anteriores (GEORGEet al, 1966, p. 23)

A análise de uma situação traria, para o geógrafo, a presença de diversas dimensões socioespaciais, que se referem a economia, a natureza, a cultura, a história, a geografia. Todos estes elementos, presentes em uma situação, não deveriam se tornar uma geografia particular. Um estudo em geografia econômica só teria sentido se considerasse a existência das diferentes dimensões daquela situação. Tais dimensões, neste raciocínio, não eram apenas partes de um todo, mas teriam sentido em relação e em movimento. Seria a situação, desse modo, que permitiria ao geógrafo produzir a síntese, sempre provisória, acerca da realidade estudada.

Nesta lógica, outro elemento explicativo, que permitiria compreender as complexidades envolvidas nos processos de formação de uma situação era o conceito de escala geográfica, que permitiria produzir uma correlação de fenômenos que iriam além de uma mera fotografia instantânea da situação a ser analisada. A partir deste conceito poderia se compreender que uma situação é resultado de processos que ocorrem em diferentes escalas geográficas, desde o local ao global, passando por uma série de intermediações.

Em um mundo aparentemente estável, não havia a preocupação de se estudar uma situação para além da escala local. Em um mundo no qual as bases técnicas e políticas permitem que processos ocorram de forma simultânea, resultando naquilo que Santos (2008) conceitou como horizontalidades e verticalidades, para se produzir uma síntese geográfica a partir da situação e da conexão de fenômenos faz-se necessário identificar as escalas geográficas e os agentes delas relacionando-as a produção daquela realidade.

Neste sentido, a discussão que embasa o movimento da Geografia Ativa não diz respeito à busca de um objeto específico de estudo da geografia. A questão está, neste sentido, em compreender qual contribuição a geografia enquanto campo disciplinar pode dar na interpretação da realidade e na formação dos sujeitos. E para tanto cabe construir os fundamentos teóricometodológicos específicos deste campo do saber. Não se trata de compreender o mundo da geografia. O que está em jogo é a nossa capacidade de entender a geografia do mundo.

E aqui há um ponto fundamental para se pensar o raciocínio geográfico e o ensino de geografia. Mesmo sem ter escrito obras diretamente relacionadas ao tema, tais autores nos apontam caminhos interessantes de discussão. Como dissemos, os autores não buscam definir um objeto 
específico da geografia, mas a definir ao que seria um olhar geográfico sobre este objeto, em termos semelhantes aqueles discutidos pelos autores apresentados na seção anterior deste artigo. Não se trata de ensinar temas "especificamente geográficos", mas de possibilitar, por meio de situações didáticas, exemplos, comparações, metodologias de ensino, a construção de um raciocínio geográfico de interpretação do mundo.

Nesta concepção de fazer geografia que pressupõe uma concepção do ensino desta disciplina está clara a indissociabilidade entre ensino e pesquisa. Para que o professor possa construir as possibilidades de elaborar raciocínios geográficos com os seus alunos, precisa dominar os fundamentos teóricos e metodológicos desta ciência. Se lidas com atenção, as propostas do movimento da geografia ativa trazem importantes desafios no que diz respeito à formação de professores de geografia na atualidade, em um momento de avanço de perspectiva tecnoinstrumentais.

\section{A geopolítica do raciocínio geográfico: de Lacoste aos tempos atuais}

Portanto, até aqui foi possível perceber que, em diferentes perspectivas, o desenvolvimento do raciocínio geográfico como princípio teórico-metodológico da geografia tem ocupado lugar de destaque na história e na epistemologia deste campo do conhecimento. No entanto, quando verificamos o debate sobre este tema expresso no documento final da BNCC, pouco ou nada desta discussão epistemológica aparece. O raciocínio geográfico surge desconectado de contexto, como um fato, nos termos de Bachelard, que pode resultar em mais um obstáculo epistemológico da geografia. Em nossa perspectiva, o esvaziamento do debate epistemológico do conceito de raciocínio geográfico na BNCC cumpre importante função estratégica, em consonância com o projeto político que este documento curricular corrobora. E para compreender tal função, pensamos ser importante retomar as críticas e análises construídas por Yves Lacoste acerca da relação entre geografia, educação e geopolítica.

Escrito ainda na década de 1970, o texto de Lacoste "A Geografia, isso serve, em primeiro lugar, para fazer a Guerra", discute os usos geopolíticos e militares do conhecimento geográfico no decorrer da história, demonstrando como a geografia, antes de se consolidar como conhecimento na escola e na universidade, vem sendo utilizada como saber estratégico, diretamente relacionado com processos de domínio e expansão territorial. Para tanto, demonstra como durante a Guerra do Vietnã conhecimentos de diferentes campos da geografia, como a geomorfologia, foram utilizados com o intuito de obter vantagens para os EUA contra os vietcongues. A grande questão posta por Lacoste em sua análise diz respeito a transformação deste saber estratégico em saber desinteressante e aparentemente apolítico.

E esta transformação, em nossa perspectiva, continua a dar o tom ao conceito de raciocínio geográfico presente na BNCC. No caso do documento do ensino fundamental, tal conceito é apresentado desacompanhado de debate sobre sua origem e acerca do lugar que ele ocupa no processo de consolidação da geografia como conhecimento na escola e na universidade. Não há densidade histórica e epistemológica sobre o conceito proposto no documento curricular, nem problematizações sobre suas diferentes leituras e interpretações a partir de diversas posições teórico-metódicos da geografia e do seu ensino. Assim, o conceito é apresentado de forma fechada, no interior de uma racionalidade técnico-instrumental, definido a partir de sua aplicabilidade, como podemos verificar no excerto a seguir retirado da BNCC para o ensino fundamental: 
Para fazer a leitura do mundo em que vivem, com base nas aprendizagens em Geografia, os alunos precisam ser estimulados a pensar espacialmente, desenvolvendo o raciocínio geográfico. O pensamento espacial está associado ao desenvolvimento intelectual que integra conhecimentos não somente da Geografia, mas também de outras áreas (como Matemática, Ciência, Arte e Literatura). Essa interação visa à resolução de problemas que envolvem mudanças de escala, orientação e direção de objetos localizados na superfície terrestre, efeitos de distância, relações hierárquicas, tendências à centralização e à dispersão, efeitos da proximidade e vizinhança etc. (BRASIL, 2017, p.359)

No documento, o raciocínio geográfico surge menos como um princípio metódico, fundamento dos processos de ensinar-aprender geografia e mais como uma habilidade, a ser desenvolvida pelos estudantes na resolução de problemas. Não há, no documento, a preocupação em problematizar as relações entre pensamento espacial e raciocínio geográfico, bem como as possíveis relações destes com as diferentes categorias e conceitos historicamente constituídos na geografia como ciência e como disciplina escolar. Tanto o raciocínio geográfico, como paisagem, espaço, território etc., são apresentados como fatos e não conceitos, revelando um intenso processo de esvaziamento epistemológico do documento curricular.

Tal situação é ainda mais grave no documento para o ensino médio. Nele, o raciocínio geográfico aparece como uma habilidade, conforme podemos verificar a seguir:

EM13CHS206: Compreender e aplicar os princípios de localização, distribuição, ordem, extensão, conexão, entre outros, relacionados com o raciocínio geográfico na análise da ocupação humana e da produção do espaço em diferentes tempos) (BRASIL, 2018)

Quando analisamos algumas das habilidades apresentadas nos documentos, é possível verificar certos efeitos deste esvaziamento epistemológico na própria construção argumentativa proposta. A seguir, temos um exemplo de habilidade, indicada para estudantes do $8^{\circ}$ ano:

(EF08GE06) Analisar a atuação das organizações mundiais nos processos de integração cultural e econômica nos contextos americano e africano, reconhecendo, em seus lugares de vivência, marcas desses processos (BRASIL, 2017)

É interessante notar como esta habilidade se refere ao papel das organizações mundiais no continente americano e africano. Ao invés de falar de exploração, violação de direitos, espoliação, expropriação, tal ação é tratada como integração cultural. É isso o que fazem Banco Mundial, Fundo Monetário Internacional, Organização Mundial do Comércio, Organização para Cooperação e desenvolvimento econômico em suas ações geopolíticas nestes continentes? Qual o papel de tais organizações na reprodução de violências, marca dos novos colonialismos nestes continentes? A mesma interpretação pode ser feita da habilidade seguinte:

(EF09GE05) Analisar fatos e situações para compreender a integração mundial (econômica, política e cultural), comparando as diferentes interpretações: globalização e mundialização (BRASIL, 2017)

Novamente, o conceito de integração é utilizado para explicar outros dois conceitos, com importante histórico de debates na epistemologia geográfica moderna: globalização e mundialização. Pensar a globalização em termos de integração é ressaltar o seu caráter de fábula, nos termos propostos por Santos (2000), ocultando o movimento dialético que revela as contradições deste processo, bem como tensiona sua superação. No entanto, não nos parece ser esta a perspectiva adotada pelos elaboradores da BNCC ao optarem pelo entendimento do mundo contemporâneo 
menos pelos conflitos que revelam dimensões de classe, raça e gênero e mais pela leitura integracionista, própria do pensamento neoliberal hegemônico.

Neste sentido, é possível verificar que, em nenhum momento dos documentos da BNCC, o amplo debate sobre o raciocínio geográfico ganha corpo. Ao contrário, verifica-se um texto com pouco preocupação epistemológico, que apresenta conceitos e categorias dissociados dos processos e contextos sociais. A própria ausência de referências bibliográficos no documento é um dos indicativos deste esvaziamento. No interior de uma lógica técnico-instrumental, a BNCC apresenta uma geografia sem geografia, sem contexto, sem história, sem conflito, configurando-se, portanto, em um obstáculo epistemológico nos termos propostos por Bachelard. Não se, trata, porém, de ingenuidade de seus elaboradores. É projeto político-ideológico e que tem, como pano, uma concepção de formação docente, o que buscaremos discutir na seção final deste texto.

\section{Considerações finais}

Em diferentes textos (GIROTTO, 2017; GIROTTO, 2018a; 2018b), temos nos posicionado contrários a adoção de uma Base Nacional Comum Curricular. Nesta crítica, evitamos adentrar o debate de conteúdo do documento, com o risco de desviarmos o foco para aquilo que, em diálogo com Apple (2000), consideramos central no debate: a forma do currículo. Se, neste artigo, avançamos as fronteiras e adentramos o campo da análise do conteúdo do documento, assim o fazemos por entender que tais conteúdos revelam formas e intencionalidades. Isso significa dizer que por detrás da ingenuidade do conceito de raciocínio geográfico expressa na BNCC não há nenhuma ingenuidade do projeto político que ele representa e dos riscos que traz para todos e todas que defendem o direito a educação pública, gratuita e de qualidade socialmente referenciada.

Como demonstramos, mesmo que de forma breve, o debate sobre o raciocínio geográfico tem atravessado a história e a epistemologia da geografia. Diante disto, não há razões objetivas para ignorar a complexidade dele na construção de um dos documentos que pretende nortear o ensino de geografia no Brasil. Dada tais circunstâncias, é preciso encontrar as razões de tal escamoteamento na intencionalidade política e econômica da BNCC, da qual o capítulo sobre geografia não escapa.

Desde o início, a BNCC tem um objetivo principal: incidir sobre as políticas de formação de professores, conforme explicitado em diferentes documentos de organismos internacionais como o Banco Mundial e a OCDE (aqueles da integração) (GIROTTO, 2017). Trata-se de redefinir a docência no interior de uma lógica de saber instrumental, esvaziando-a da complexidade própria desta profissão, conforme aponta Freire (1996) e Tardif (2008). Reduzido a um mero executor de currículo, o professor passa a ser alvo predileto de prescrições curriculares como aqueles presentes na BNCC.

E esta intencionalidade se revela cada vez mais presente quando vemos aprovadas medidas como a Base Nacional Comum Curricular de Formação de professores², que atrela os currículos das licenciaturas às prescrições curriculares da BNCC. A partir deste documento, os conceitos e conteúdos presentes na BNCC passam a ser também a base da formação de professores. E isso, no caso da geografia, deve nos preocupar ainda mais, dada a baixa qualidade epistemológica do texto expresso no documento nacional.

Em nossa perspectiva, o esvaziamento epistemológico do debate sobre raciocínio geográfico na BNCC está coerentemente relacionado com a lógica de formação de professores induzida pelo

\footnotetext{
2 Regulamentada pela Resolução nº 2 do Conselho Nacional de Educação, de 20 de dezembro de 2019, que define as Diretrizes Curriculares Nacionais para a Formação Inicial de Professores para a Educação Básica e institui a Base Nacional Comum para a Formação Inicial de Professores da Educação Básica (BNC-Formação).
} 
documento. Como um conjunto de prescrições, a BNCC reproduz a ideia do professor como técnico, incapaz de pensar acerca dos conhecimentos do ensino, dos procedimentos, métodos, análises e, portanto, alguém que demanda um currículo único, padronizado, engessado. Nestes termos, esvaziado do sentido de pesquisador de sua própria prática e da ciência de que partilha, a lógica docente hegemônica na BNCC interessa aos principais grupos privados de produção de material didático que encontrarão, neste docente precarizado em suas condições de formação e trabalho, o principal consumidor de sua rentável mercadoria.

A estrutura do documento revela esta lógica: após um breve texto, esvaziado de debates epistemológicos, com uma série de frases de efeito que pouco revelam dos conflitos, contradições e disputam que marcam os campos do conhecimento, segue-se uma lista de habilidades, todas elas acompanhadas de siglas. Há que ressaltar que tais siglas, provavelmente, servirão de referência no momento de elaboração das avaliações padronizadas, outro momento da lógica técnico-instrumental de educação da qual a BNCC é um dos elementos constituintes.

Portanto, como hegemonia, a BNCC expressa uma lógica de formação docente, de escola, de educação instrumental, com o intuito de esvaziar de conflitos, contradições, de crítica e de transformação os espaços-tempos do currículo. No entanto, há sempre espaços-tempos contra hegemônicos quando se trata de escola, dos sujeitos e da geografia. É nestes espaço-tempos de contra hegemonia que precisamos reivindicar a docência como ato criativo, a escola como território de sentidos e a geografia como potência, no sentido dado ao termo por Lacoste (1993): saber pensar o espaço, para nele se organizar e combater. E para isso, é fundamental subverter o conceito de raciocínio geográfico expresso na BNCC.

Em nossa perspectiva, o raciocínio geográfico é o movimento de pensamento e formação que possibilita aos sujeitos desenvolverem consciência da condição espacial de si e dos diferentes fenômenos com os quais se relacionam. Se a condição espacial é natural, um a priori da existência, independendo do reconhecimento dos sujeitos, a consciência espacial é sempre construção social, mediada por diferentes processos, dentre os quais, a educação formal por meio da escola. 0 desenvolvimento da consciência espacial, como um dos resultados do desenvolvimento de raciocínios geográficos cada vez mais complexos, é, em nossa perspectiva, um dos principais objetivos do ensino de geografia na educação básica.

No entanto, para que possamos avançar neste debate, é fundamental reconhecer a própria condição espacial da sociedade em vivemos. O modo de produção capitalista, desde sua origem, é marcado por contínuos processos de expropriação espacial. Os cercamentos na Inglaterra, as invasões nos territórios indígenas na América, os processos de escravidão na África, são exemplos bastante evidentes desta lógica de expropriação territorial sem a qual o modo de produção capitalista não poderia ter se desenvolvido e se tornado hegemônico. No entanto, não se trata apenas de um momento histórico deste modo de produção, restrito a certos lugares. Ao contrário, faz parte de seu princípio constituinte. Para sua existência, o modo de produção capitalista, como aponta Marx (2013) ao analisar aquilo que denominou de acumulação primitiva do capital, precisa constituir duas classes de sujeitos sociais: de um lado, os homens e mulheres proprietários dos meios de produção; de outro, aqueles e aquelas que foram expropriados de tais meios, restando-lhes a opção de vender a forçade-trabalho para que possam sobreviver. É esta relação desigual de produção que funda o capitalismo como modo de produção.

Quando nos perguntamos acerca dos múltiplos significados do termo expropriação, é importante destacar que se trata também de uma expropriação espacial. A constituição políticojurídica da propriedade privada como um dos elementos da dinâmica capitalista tem como objetivo reproduzir esta condição constante de expropriação. Por isso, é fundamental questionar: qual o lugar 
do raciocínio geográfico em uma sociedade que se funda e se reproduz a partir da expropriação espacial e na alienação desta expropriação? Esvaziar o debate acerca do raciocínio geográfico de seu conteúdo político-estratégico, como faz a Base Nacional Comum Curricular, é contribuir para que a alienação espacial se consolide e pouco possamos fazer, como docentes e discentes na educação básica, na direção de problematizar os fundamentos desta sociedade.

Assim, é fundamental que compreendamos como os processos de expropriação espacial se reproduzem agora, em diferentes escalas espaço-temporais. Isso pressupõe analisar os diferentes sujeitos do raciocínio geográfico e as estratégias que constroem com o intuito de reproduzir interesses econômicos, político e sociais. É interessante notar como os processos de controle espacial tem se intensificando nos últimos anos. A geolocalização dos diferentes aparelhos eletrônicos é um bom exemplo deste processo. Geolocalizados, cada um dos sujeitos produz informações espaciais da qual pouco entendem, mas que são centrais nos processos de controle espacial. Se no capitalismo as informações valem, as informações geolocalizadas valem muito mais, uma vez que permitem acessar, em detalhe, comportamentos e trajetórias de sujeitos reais em lugares reais. São a base para que os agentes transnacionais do capital possam construir conexões espaciais estratégicas para as lógicas de reprodução ampliada. Há, portanto, que reconhecer, retomando a obra de Lacoste (1993), que o raciocínio geográfico continua a ser uma saber-poder em disputa

Por isso, é cada vez mais importante que os debates sobre o raciocínio geográfico no ensino de geografia saiam dos limites estreitos das fronteiras curriculares, cada vez mais hegemonizados pelos discursos técnico-instrumentais de competências e habilidades, e sejam postos no centro dos debates epistemológicos do fazer geográfico, reconhecendo sujeitos, contextos, intencionalidades na atual dinâmica do modo de produção capitalista. Isso significa reconhecer que o raciocínio geográfico, como saber-poder, estratégico, continua sendo apropriado por um conjunto restrito de sujeitos sociais que, por sua vez, têm todo interesse em reproduzir tais privilégios, uma vez que o acesso a raciocínios geográficos complexos está na base dos atuais processos de reprodução ampliada do capital.

Ao tomarmos este pressuposto, podemos construir problematizações contínuas que nos ajudem a superar os discursos aparentemente ingênuos presentes nos debates acerca do raciocínio geográfico, como aqueles expostos na BNCC, e apontemos caminhos na direção de compreender que construir raciocínios geográficos desde a escola pública pressupõe discutir os fundamentos de uma sociedade que reproduz, constantemente, expropriação e alienação espacial.

Sem esta perspectiva, corremos o risco de reproduzir uma geografia, apesar das roupagens novas, conservadora e pouco capaz de contribuir na formação de sujeitos que leem, problematizam e transformam o mundo em direção à consciência espacial e ao direito de todos e todas à geografia como experiência individual e como fundamento da vida coletiva. 


\section{Referências}

APPLE, M. (2000) Educação e Poder. Porto Alegre: Artmed.

BACHELARD, G. (1996) A formação do espírito científico. Rio de Janeiro: Contraponto.

BRASIL. (2017) Base Nacional Comum Curricular do Ensino Fundamental. MEC: Brasília.

(2018) Base Nacional Comum Curricular do Ensino Médio. MEC: Brasília.

CARVALHO, D. de. (1945) O sentido geográfico. Boletim Geográfico, ano III, n. 25, p. 3-7.

CLAVAL, P. (2010) Terra dos Homens. São Paulo: Contexto.

FREIRE, P. (1987) Pedagogia do oprimido. 38a edição. São Paulo: Paz e Terra.

(1996) Pedagogia da Autonomia. 27a edição. São Paulo: Paz e Terra.

GEORGE, P. et al. (1966) A Geografia Ativa. São Paulo: DIFEL.

GIROTTO, E. D. (2017) Dos PCNs a BNCC: o ensino de geografia sob o domínio neoliberal. GeoUerj, n. 30, p. 419-439.

(2018a) Entre o cinismo e a hipocrisia: o novo ciclo de reformas educacionais no Brasil. Educar e Revista, v. 34, n. 71, p. 159-174

(2018b) Entre o abstracionismo pedagógico e as escolas de luta: a base nacional comum curricular e a defesa da escola pública. Horizonte, vol. 36, n. 1, p. 16-30.

GOMES, P. C. da. (2017) Quadros Geográficos: uma forma de ver, uma forma de pensar. Rio de Janeiro: Bertrand Brasil.

LACOSTE, Y. (1993) A geografia, isso serve, em primeiro lugar, para fazer a guerra. Campinas, SP: Papirus.

MARX, K. (2013) O Capital: para a crítica da economia política. Livro I, volume II, RJ: Civilização Brasileira.

SANTOS, M. (2000) Por uma outro globalização. Rio de Janeiro: Record.

TARDIF, M. (2008) Saberes docentes e formação profissional. Petrópolis, RJ: Vozes.

WULF, A. (2016) A invenção da natureza. A vida e as descobertas de Alexander Von Humboldt. São

Paulo: Planeta. 